\title{
Serum antibodies to Helicobacter hepaticus and Helicobacter pylori in patients with chronic liver disease
}

I Nilsson, S Lindgren, S Eriksson, T Wadström

\begin{abstract}
Background-Bile tolerant helicobacter species such as $H$ hepaticus and $H$ bilis have frequently been reported to cause hepatitis in mice and other rodents.

Aims-To investigate the possible pathogenic role of these and other helicobacter species in chronic liver disease in humans. Methods-Serum samples from 144 patients with various chronic liver diseases, 30 patients with primary sclerosing cholangitis (PSC), and 48 healthy blood donors were analysed for antibodies against $\boldsymbol{H}$ hepaticus murine strain CCUG 33637 and $H$ pylori strain CCUG 17874. Cell surface proteins of $\boldsymbol{H}$ hepaticus were extracted by acid glycine buffer and used in an enzyme immunoassay (EIA) and immunoblot (IB).

Results-56 of 144 (39\%) patients with chronic liver diseases and six of $30(20 \%)$ with PSC showed increased antibody concentrations in the $H$ hepaticus EIA; in the $H$ pylori EIA the numbers were $58 \%$ and $13 \%$ respectively. Compared with the healthy blood donors the antibody reactivity against the two helicobacter species was not increased $(46 \%$ and $48 \%$ respectively). Patient serum samples retested by the $H$ hepaticus EIA after absorption with sonicated $\boldsymbol{H}$ pylori cells remained positive in 12 of $37(33 \%)$ serum samples. Distinct antibody reactivity to $55-65 \mathrm{kDa}$ proteins was observed by $H$ hepaticus IB, after the absorption step, and was considered specific for $H$ hepaticus. These 12 serum samples were from patients with chronic alcoholic liver disease.

Conclusions-Antibodies to $H$ hepaticus, often cross reacting with $\boldsymbol{H}$ pylori, occur frequently in patients with chronic liver diseases, with no clear cut relation to specific diagnostic groups. The pathogenic significance of these findings is not known. (Gut 2000;46:410-414)
\end{abstract}

GastroenterologyDepartment of Medicine, University Hospital of Malmö, Sweden

$S$ Lindgren

S Eriksson

Correspondence to: Dr I Nilsson, Medical

Microbiology, University of Lund, Sölvegatan 23 ,

S-223 62 Lund, Sweden

Accepted for publication 5 October 1999

Helicobacter hepaticus was discovered in 1992 at the National Cancer Institute-Fredrick Cancer Research and Development Centre (NCIFCRDC) and first isolated from a colony of $\mathrm{A} / \mathrm{JCr}$ mice, a low liver tumour incidence mouse strain with a high incidence of severe hepatocellular tumours in aged animals. ${ }^{12}$
Neither chemicals nor virus induced the tumours but $H$ hepaticus was isolated and cultured from liver suspensions. Healthy mice were injected intraperitonally with $H$ hepaticus and the organisms were recovered from the extracellular space of hepatic bile canaliculi. The intrahepatic biliary system was also infected with $H$ hepaticus, thus likely to be the aetiological agent of chronic hepatitis and associated with hepatocellular tumours in this colony of aged mice.

Adenocarcionoma of the stomach is the second most prevalent of all human malignancies worldwide and associated with infection, at an early age, with $H$ pylori ${ }^{3}$; chronic atrophic gastritis is known to be a precursor of gastric cancer. ${ }^{4}$ Little is known about the possible role of helicobacter species in human liver disease but $H$ pylori DNA has been detected in bile samples by polymerase chain reaction. ${ }^{5}$ Fox and colleagues ${ }^{6}$ recently published a study on the possible role of $H$ hepaticus, $H$ bilis, and other bile tolerant helicobacters in chronic cholecystitis and liver disease. Studies of the $H$ hepaticus syndrome of chronic hepatitis and liver tumours in mice may give new insights into the possible role of helicobacter species other than $H$ pylori in human stomach cancer, gastric lymphoma, and chronic liver diseases.

The aims of the present study were to analyse the antibody response against cell surface proteins of $H$ hepaticus (murine strain CCUG 33637) in two different patient groups: chronic liver diseases of various aetiologies; and primary sclerosing cholangitis, a chronic inflammatory liver disorder primarily affecting the bile ducts. $H$ hepaticus antibody prevalence was compared with the prevalence of $H$ pylori antibodies in the same patient groups and in healthy blood donors. In addition, cross reactivity between antigens of the two helicobacter species was analysed.

Materials and methods

PATIENT SAMPLES

Serum samples from patients with various chronic liver diseases ( $n=144$, age $31-88$ years) were analysed. They represented a two year prospective series of patients investigated at the Department of Medicine, University Hospital of Malmö for suspected chronic liver disease
Abbreviations used in this paper: CLD, chronic liver disease; EIA, enzyme immunoassay; ERC, endoscopic retrograde cholecystography; IB, immunoblot; PCR; polymerase chain reaction; PSC, primary sclerosing cholangitis; RAA, relative antibody activity. 
(CLD) owing to increased concentrations of liver enzymes and/or clinical symptoms of more than six months duration. ${ }^{8}$ Thirty patients with primary sclerosing cholangitis (PSC) ${ }^{9}$ were also included. The diagnosis was verified in all cases by endoscopic retrograde cholecystography (ERC). Thirty per cent of the patients had alcoholic liver disease, 20\% autoimmune liver disease (primary biliary cirrhosis, autoimmune hepatitis, and primary sclerosing cholangitis) and $10 \%$ cryptogenic liver disease. Other diagnostic groups were chronic viral hepatitis, metabolic liver disease, systemic disease, drug reactions, malignant disease, and heart failure.

Blood donor serum samples $(n=48)$ randomly collected at the Blood Transfusion Unit at the University Hospital of Malmö, served as controls. All serum samples were kept frozen at $-20^{\circ} \mathrm{C}$ until analysed.

BACTERIAL STRAINS AND CULTURE CONDITIONS $H$ hepaticus, a murine liver isolate (strain CCUG 33637) was cultured on Fastidious agar (Amersham Pharmacia Biotech, Rainham, UK), and grown for 7-10 days in a microaerophilic atmosphere $\left(3 \% \mathrm{H}_{2}, 10 \%\right.$ $\mathrm{CO}_{2}, 5 \% \mathrm{O}_{2}, 82 \% \mathrm{~N}_{2}$ ) at $37^{\circ} \mathrm{C}$. Agar plates were examined for colonies with a green metallic transparent surface, and tested positive for urease, catalase, and oxidase enzyme activities.

PREPARATION OF CELL SURFACE ANTIGENS FOR ENZYME IMMUNOASSAY AND IMMUNOBLOT

Ten agar plates $(\Phi 5 \mathrm{~cm})$ with confluent bacterial growth were harvested and washed once in $10 \mathrm{mM}$ phosphate buffered saline (PBS) $\mathrm{pH}$ 7.2 , with a total cell yield of $0.6 \mathrm{~g}$ wet weight. Cell surface antigens were extracted using a standard method with $0.2 \mathrm{M}$ acid glycine buffer $\mathrm{pH} 2.2$ as described previously. ${ }^{10}$ The protein concentration was $290 \mu \mathrm{g}$ per $\mathrm{ml}$ as determined by the BioRad protein assay (BioRad, Richmond, UK). The protein profile of $H$ hepaticus was compared with acid glycine extracted cell surface proteins of $H$ pylori (CCUG 17874) by sodium dodecyl sulphate polyacrylamide gel electrophoresis (SDSPAGE $)^{11}$ followed by silver staining.

H HEPATICUS ENZYME IMMUNOASSAY (IgG-EIA) The $H$ hepaticus enzyme immunoassay (EIA) was performed as described for $H$ pylori EIA. ${ }^{12}$ In brief, Maxisorp immunoplates (NUNC, Roskilde, Denmark) were coated with $100 \mu \mathrm{l}$ per well with a protein concentration of $5 \mu \mathrm{g}$ per $\mathrm{ml}$; serum diluted $1 / 800$ was added and the plates were incubated for 90 minutes at $37^{\circ} \mathrm{C}$. An alkaline phosphatase goat antihuman antibody (Sigma, St Louis, Missouri, USA) was used as the second antibody. After repeated washings, $100 \mu \mathrm{l}$ per well of a substrate solution containing $p$-nitrophenyl phosphate (Sigma), diethanolamine, and $\mathrm{MgCl}$ was added. The EIA test results are expressed as corrected mean absorbance values (A 405 $\mathrm{nm}$ ) in per cent of a reference standard (human gammaglobulin, Pharmacia \& Upjohn, Stockholm, Sweden). A relative antibody activity (RAA value) greater than 35 and less than 25 units was defined as positive and negative, respectively; values in between were regarded as low positive values (borderlines). The cut off values are based on EIA and immunoblot analyses of serum samples from patients with positive and negative gastric culture for $H$ pylori, healthy blood donors, and children. ${ }^{10} 12$ Similar IgG EIA analyses were performed with acid glycine extracted cell surface proteins of $H$ pylori.

IMMUNOBLOT (IgG)

In the immunoblot assay, acid glycine extracted cell surface proteins of $H$ hepaticus were separated by SDS-PAGE with an $8-18 \%$ gradient (ExelGel, Pharmacia Biotech $\mathrm{AB}$, Uppsala, Sweden) according to the Pharmacia manual. Proteins were electroblotted onto a PVDF membrane (Millipore, Intertech, Bedford, Massachusetts, USA), and subsequent blocking and probing with patient and control serum samples were performed as described previously. ${ }^{13}$ Similar immunoblot analyses were performed with acid glycine extracted cell surface proteins of $H$ pylori.

IgA IMMUNOBLOT

As control for non-specific bacterial binding between proteins of $H$ hepaticus/H pylori and IgA, an immunoblot was performed. Strips, containing separated cell surface proteins of the two helicobacter species were overlaid with human IgA antibodies (myeloma produced) and then incubated with an enzyme conjugated anti-IgA antibody followed by substrate staining. Another two strips were probed with serum samples from $H$ hepaticus/H pylori EIA positive patients. Enzyme conjugated antihuman IgA antibodies (P216, Dako A/S, Glostrup, Denmark) were added and after incubation the strips were developed. ${ }^{13}$

IMMUNOSTAINING OF HEAT SHOCK PROTEINS (Hsp60)

Immunoblot strips containing separated $H$ hepaticus and $H$ pylori cell surface proteins respectively were probed with a polyclonal antiserum to the $H$ pylori $\mathrm{Hsp} 60$ protein. The Hsp60 protein was purified from $H$ pylori strain CCUG 17874 by gel filtration (Superose 12, Pharmacia Biotech, Uppsala, Sweden) and ion exchange chromatography (MonoQ, Pharmacia Biotech), and then used for immunisation. ${ }^{14}$ Corresponding strips were incubated with an antihuman Hsp60 serum (Santa Cruz, Biotechnology Inc., USA). Immunoblot analyses were performed as described above.

ABSORPTION EXPERIMENTS

For absorption of potential cross reacting antibodies, sonicated whole cells of $H$ pylori (CCUG 17874) were used. To $1 \mathrm{ml}$ of sonicated cells (A 540 of OD 1.0) $10 \mu$ serum was added and incubated for one hour at $22^{\circ} \mathrm{C}$ and for 16 hours at $6^{\circ} \mathrm{C}$ during constant shaking. Cells were removed by centrifugation and supernatants collected for Helicobacter serology. 


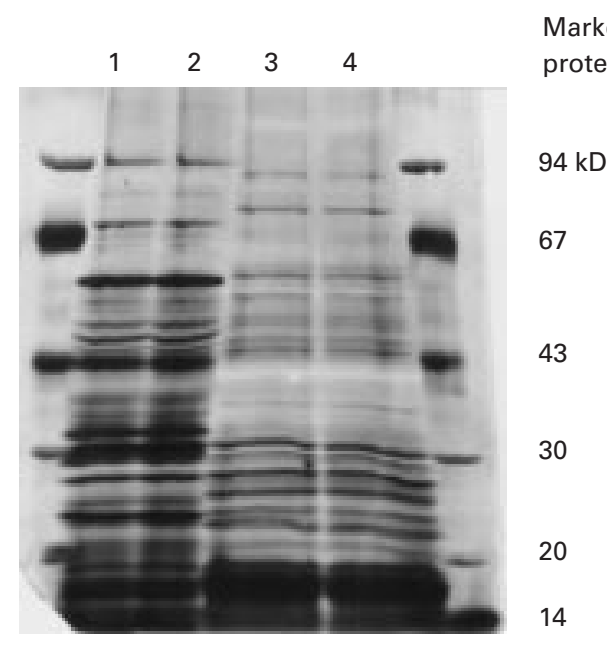

Figure 1 Protein profiles of the acid glycine extracted cell surface proteins of Helicobacter pylori (lanes 1 and 2) and Helicobacter hepaticus (lanes 3 and 4) separated by SDS-PAGE (8-18\%) and stained with silver.

Table 1 Outcome of the H hepaticus EIA and H pylori EIA in serum samples from patients with chronic liver disease (CLD) and primary sclerosing cholangitis (PSC)

\begin{tabular}{lll}
\hline & $\begin{array}{l}\text { H hepaticus EIA } \\
\text { positive }(\%)\end{array}$ & $\begin{array}{l}\text { H pylori EIA } \\
\text { positive* }(\%)\end{array}$ \\
\hline CLD $(\mathrm{n}=144)$ & $56(39)$ & $79(55)$ \\
PSC $(\mathrm{n}=30)$ & $6(20)$ & $4(13)$ \\
Controls† $(\mathrm{n}=48)$ & $22(46)$ & $24(48)$ \\
\hline
\end{tabular}

^Borderline values are included.

†Healthy blood donors.

$\mathrm{n}$, number of serum samples.

\section{Results}

Protein profiles of acid glycine extracted cell surface proteins from $H$ hepaticus were compared with a corresponding antigen preparation of $H$ pylori after silver staining of the SDSPAGE gel. Differences of the band pattern were observed with proteins migrating in the region of 43-94 $\mathrm{kDa}$ in molecular mass $\left(M_{\mathrm{r}}\right)$, whereas proteins with lower $M_{\mathrm{r}}$ showed a similar pattern (fig 1).

IgG-EIA

Antibody reactivity to extracted $H$ hepaticus cell surface proteins in serum samples from patients with chronic liver disease was initially analysed by EIA. Of 144 serum samples, 37 $(26 \%)$ showed increased antibody concentrations (RAA greater than 35 units), 19 (13\%) showed moderate values (RAA 25-35 units), and $88(61 \%)$ were negative (table 1$)$. The distribution of antibody reactivity in the diagnostic subgroups among $H$ hepaticus EIA positive patients, including primary biliary cirrhosis and other autoimmune liver diseases and cryptogenic liver disease, did not differ from the whole patient population. In the $H$ pylori EIA, 64 of $144(44 \%)$ serum samples were positive and 15 serum samples gave borderline values (table 1). Of the 30 serum samples from PSC patients, six $(20 \%)$ showed increased antibody concentrations, and $24(77 \%)$ were negative in the $H$ hepaticus EIA. In the $H$ pylori EIA four serum samples were positive (table 1 ).

Serum samples from 48 healthy blood donors were assayed in the two EIAs and the
Table 2 Cross reactivity to cell surface antigens between the two helicobacter species

\begin{tabular}{lll}
\hline & $\begin{array}{l}\text { Positive in } H \\
\text { hepaticus EIA } \\
\text { before absorption }\end{array}$ & $\begin{array}{l}\text { Positive in } H \\
\text { hepaticus EIA after } \\
\text { absorption }\end{array}$ \\
\hline Patients & 37 & 12 \\
Controls & 24 & $0(3 \dagger)$ \\
\hline
\end{tabular}

Cross reactivity to cell surface antigens between the two helicobacter species was analysed in 37 serum samples from the patients with chronic liver disease and in 24 from the controls. The serum was absorbed with sonicated whole cell material from $H$ pylori and then retested.

^Healthy blood donors.

tValues just above the lower cut off.

seroprevalence was found to be $46 \%$ for $H$ hepaticus and $48 \%$ for $H$ pylori (table 1 ).

\section{ABSORPTION EXPERIMENTS}

Cross reactivity between cell surface proteins of the two helicobacter species was analysed with 37 serum samples from patients with chronic liver diseases showing high antibody concentrations in the $H$ hepaticus EIA (14 of these were $H$ pylori EIA negative) and with 24 blood donor serum samples found positive by $H$ hepaticus EIA (three of these were $H$ pylori EIA negative). In 25 patients the $H$ hepaticus EIA became negative but 12 serum samples remained positive. These serum samples were from patients who suffered from alcoholic related liver disease. All blood donor serum samples became negative after the absorption step except three that showed low values close to the lower cut off level (table 2).

IMMUNOBLOT (IgG)

Patient serum samples absorbed with $H$ pylori whole cells and with a remaining positive value in the $H$ hepaticus EIA were further analysed by immunoblot, and the antibody reactivity was compared with results with the same serum samples that were not absorbed. In the $H$ hepaticus immunoblot the unabsorbed serum samples intensively stained proteins of 55-65 $\mathrm{kDa}$ in $M_{\mathrm{r}}$ (fig 2A). This was not observed in the immunoblot based on $H$ pylori antigens (fig 2B). When these serum samples, absorbed with sonicated $H$ pylori cells, were analysed in the $H$ hepaticus immunoblot, reactivity to the 55-65 $\mathrm{kDa}$ proteins remained (fig 2C). However, when the serum samples were probed on strips containing separated $H$ pylori proteins no reactivity was observed (figure 2D).

IMMUNOBLOT (IgA)

Patients with chronic alcoholic liver disease often show high serum IgA levels compared with healthy individuals. ${ }^{15}$ The immunoblots performed for control of a non-specific binding of bacterial cell material from $H$ hepaticus and $H$ pylori showed no visible IgA reactivity (data not shown).

IMMUNOSTAINING OF Hsp60

By immunoblot the polyclonal anti- $H$ pylori Hsp60 serum stained two major bands with an approximate $M_{\mathrm{r}}$ of $62-65 \mathrm{kDa}$ with the two helicobacter species. The antihuman Hsp60 serum weakly stained a $65 \mathrm{kDa}$ protein of $H$ pylori, and with $H$ hepaticus no bands were observed (data not shown). 
A

1233456789101112

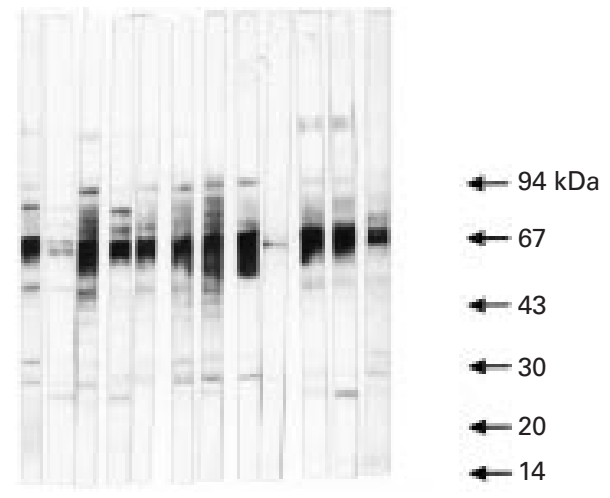

C

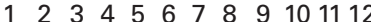

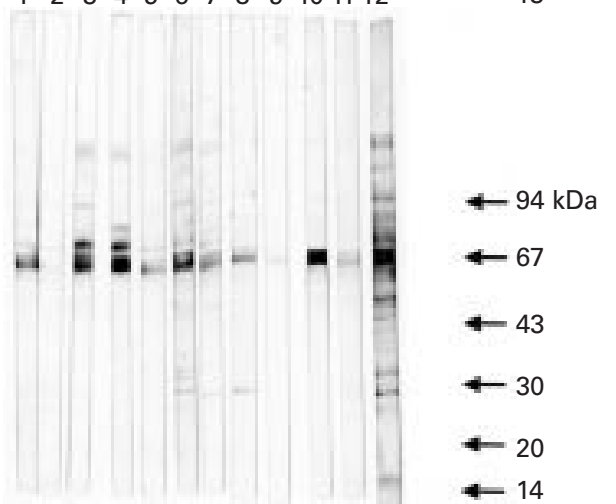

B

123345667899101112

13

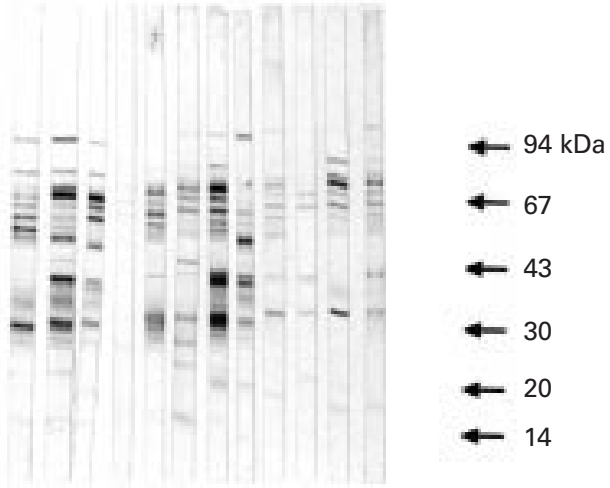

D $\begin{array}{lllllllllll}1 & 2 & 3 & 4 & 5 & 6 & 8 & 9 & 101112 & 13\end{array}$

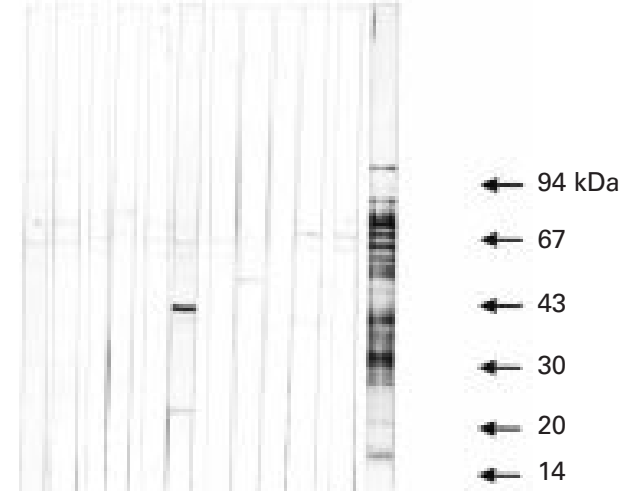

Figure 2 Antibody response to cell surface proteins of Helicobacter hepaticus ( $A$ and $C$ ) and Helicobacter pylori ( $B$ and D) was analysed by immunoblotting with serum samples from patients with chronic liver disease (lanes 1 to 11). Lane 12 represents the reference standard. In (C) and (D) serum samples were absorbed with sonicated helicobacter cells.

\section{Discussion}

Antibodies against $H$ hepaticus and $H$ pylori were detected in serum samples from patients with various liver diseases. The frequency of antibody reactivity was, however, not increased in any specific diagnostic groups and serum positivity was not increased in patients with chronic liver diseases compared with the healthy individuals. Some of these antibodies may represent cross reactivity between the two species, while a specific antibody response to cell surface proteins of $H$ hepaticus was detected in serum samples from patients with alcoholic related liver disease.

Several new species of the genus helicobacter have recently been identified in various mammals, with some species inducing gastrointestinal infection while others seem to colonise the gastrointestinal tract without causing infection and tissue inflammation. ${ }^{16-18}$ Recent reports on multifocal hepatitis in dogs ${ }^{19}$ induced by bile tolerant helicobacter, suggested that helicobacter organisms with liver tropism may also cause hepatitis in humans and other primates. However, up to now no human liver bile duct isolates of helicobacter have been reported although bile samples were shown to contain $H$ pylori DNA. ${ }^{5}$ In susceptible strains of mice, $H$ hepaticus causes an acute focal hepatitis, which progresses to chronic hepatitis with the presence of relatively few infectious organisms. ${ }^{20}$ Franklin and colleagues $^{21}$ reported on a novel helicobacter species, $H$ cholecystus, isolated from the bile tract of Syrian hamsters with chronic gall bladder inflammation and pancreatitis. Interestingly, Siringo and colleagues ${ }^{22}$ reported a high prevalence of $H$ pylori infection in cirrhotic patients, which was not confirmed by Tsai. ${ }^{23}$ Thus, it is possible that not yet isolated urease positive as well as urease negative helicobacter species may be able to colonise the human intestinal tract, as recently described in dogs and cats. ${ }^{24}$ Fox and colleagues ${ }^{6}$ concluded that helicobacter might induce a chronic gall bladder inflammation in humans with late sequelae such as bile tract and gall bladder malignancies, and a potential role of $H$ hepaticus, $H$ bilis, and other bile tolerant helicobacter species in chronic cholecystitis and liver disease. The importance of further studies on the possible role of these new helicobacter species in human liver disease was emphasised as was the need to develop non-invasive serological assays to determine the seroprevalence of hepatic helicobacter infections.

It is assumed that bile tolerant helicobacter species are antigenically and genetically similar. Our findings in this study, showing 12 patient serum samples with high antibody reactivity to cell surface proteins of $H$ hepaticus even after absorption with $H$ pylori, indicate that some helicobacter-like organism may be involved in human liver diseases. By immunoblotting, antibodies mainly reacted to the 55-65 $\mathrm{kDa}$ proteins and at least two of these 
proteins were recognised by an anti- $H$ pylori Hsp60 antibody, suggesting that patient serum samples intensively staining the $60-65 \mathrm{kDa}$ proteins of $H$ hepaticus contained increased concentrations of antibodies to helicobacter Hsp60 proteins (fig 2A). Hsps are highly conserved, immunogenic molecules induced by heat, inflammatory mediators, and other forms of physiological stress ${ }^{25}$; ethanol might be such a factor. The pathogenic mechanism of this finding is unknown, but it is a fact that ethanol abuse induces a local immune defect and activation of a latent helicobacter infection. Ward and colleagues ${ }^{26}$ found that antibodies to helicobacter (Hsp70) immunoreacted with hepatocytes from infected mice livers and thus could be responsible for autoimmune mediated hepatic lesions of bile duct epithelium infected with $H$ hepaticus.

In conclusion, antibodies to $H$ hepaticus, often cross reacting with $H$ pylori, were detected in serum samples from patients with alcoholic related liver disease. The antibody response to $H$ hepaticus proteins with $M_{\mathrm{r}}$ of 60-65 kDa remained even after absorption experiments. Attempts to culture strains from human liver biopsy specimens and bile samples will be an attractive approach, together with improved serological assays, to explore further the possible role of bile tolerant helicobacters in various biliary tract and liver diseases.

This project was supported by grants from the Swedish Medical Research Council (16x04723), the University Hospital of Lund, and the Forssman Foundation. Part of this study was reported at EASL, Lisbon, April 1998 ( $\mathcal{F}$ Hepatol 1998;(suppl 1):28, at EASL, Lisbon, April 1998 (F Hepatol 1998;(suppl 1):28, on Gastroduodenal Pathology and Helicobacter pylori, Budaon Gastroduodenal Pathology and Helicobacter pylori, Budapest, 2-5

1 Ward JM, Fox JG, Anver MR, et al. Chronic active hepatitis and associated liver tumors in mice caused by a persistent and associated liver tumors in mice caused by a persistent bacterial infection with a novel

2 Fox JG, Li X, Yan L, et al. Chronic proliferative hepatitis in $\mathrm{A} / \mathrm{JCr}$ mice associated with persistent Helicobater hepaticus infection: a model of Helicobacter-induced carcinogenesis. Infect Immun 1996;64:1548-58.

3 Blaser MJ, Perez-Perez GI, Kleanthous H, et al. Infection with Helicobacter pylori strains possessing cagA is associated with an increased risk of developing adenocarcinoma of the stomach. Cancer Res 1995;55:2111-15.

4 Kuipers EJ, Perez-Perez GI, Meuwissen SG, et al. Helicobacter pylori and atrophic gastritis: importance of the cagA status. F Natl Cancer Inst 1995;87:1777-80.

5 Lin T-T, Yeh C-T, Wu C-S, et al. Detection and partial sequence analysis of Helicobacter pylori DNA in the bile samples. Dig Dis Sci 1995;40:2214-19.
6 Fox JG, Dewhirst FE, Shen Z, et al. Hepatic Helicobacter species identified in bile gallbladder tissue from Chileans with chronic cholecystitis. Gastroenterology 1998;114:75563.

7 Blaser M. Helicobacter and biliary tract disease. Gastroenterology 1998;114:840-2.

8 Verbaan $\mathrm{H}$, Hoffmann G, Lindgren S, et al. Long-term outcome of chronic hepatitis $\mathrm{C}$ infection in a low-prevalence area. Scand f Gastroenterol 1998;33:650-5.

9 Broomé U, Olsson R, Loof L, et al. Natural history and prognostic factors in 305 Swedish patients with primary sclerosing cholangitis. Gut 1996;38:610-15.

10 Lelwala-Guruge J, Schalén C, Ljungh Å, et al. Detection of antibodies to Helicobacter pylori cell surface antigens. Scand F Infect Dis 1990;22:457-65.

11 Laemmli UK. Cleavage of structural proteins during the assembly of the head of bacteriophage T4. Nature $1970 ; 227: 680-5$.

12 Lelwala-Guruge J, Nilsson I, Ljungh Å, et al. Cell surface proteins of Helicobacter pylori as antigens in an ELISA and a comparison with three commercial ELISA. Scand $\mathcal{F}$ Infect Dis 1992;24:457-65.

13 Nilsson I, Ljungh Å, Aleljung P, et al. Immunoblot for serodiagnosis of Helicobacter pylori infections. $\mathcal{F}$ Clin Microbiol 1997;35:427-32.

14 Nilsson I. Thesis, ISBN 91-628-3218-2, Lund University, Sweden, 1998.

15 Meillet D, Labrousse F, Benoit MO, et al. Increased serum concentration of $\operatorname{IgA} \mathrm{A}_{2}$ subclass and $\operatorname{IgA} \mathrm{A}_{2} / \mathrm{IgA}_{1}$ ratio: specific markers of chronic alcoholic abuse? Eur $\mathcal{F}$ Clin Chem Clin Biochem 1997;35:275-9.

16 Jalava K, Kaartinen M, Utrainen M, et al. Helicobacter salomonis sp. nov., a canine gastric Helicobacter sp. related to Helicobacter felis and Helicobacter bizzozeroni. Int 7 Syst Bacteriol 1997;47:975-82.

17 Taylor NS, Fox JG, Yan L. In-vitro hepatotoxic factor in Helicobacter hepaticus, $\mathrm{H}$ pylori and other Helicobacter species. F Med Microbiol 1995;42:48-52.

18 Baker DG. Natural pathogens of laboratory mice, rats, and rabbits and their effects on research. Clin Microbiol Rev 1998;11:231-66.

19 Fox JG, Drolet R, Higgins R, et al. Helicobacter canis isolated from a dog liver with multifocal necrotizing hepatitis. F Clin Microbiol 1996;34:2479-82.

20 Rice JM. Helicobacter hepaticus, a recently recognized bacterial pathogen, associated with chronic hepatitis and hepatocellular neoplasia in laboratory mice. Emerging Infect Dis 1995;1:129-31.

21 Franklin CL, Beckwith CS, Livingstone RS, et al. Isolation of a novel Helicobacter species, Helicobacter cholecystus sp. nov., from the gallbladders of Syrian hamsters with cholangiofibrosis and centrilobular pancreatitis. $f$ Clin Microbiol 1996;34:2952-8.

22 Siringo S, Vaira D, Menegatti R, et al. High prevalence of Helicobacter pylori in liver cirrhosis. Relationship with clinical and endoscopic features and the risk of peptic ulcer. Dig Dis Sci 1997;42:2024-30.

23 Tsai C-J. Helicobacter pylori infection and peptic ulcer disease in cirrhosis. Dig Dis Sci 1998;43:1219-25.

24 Lecoindre P, Chevallier M, Peyrol S, et al. Pathogenic role of gastric Helicobacter $\mathrm{sp}$ in domestic carnivores. Vet Res 1997;28:207-15.

25 Barton SGRG, Winrow VR, Rampton DS, et al. Circulating antibodies to the $60-\mathrm{kD}$ heat shock protein (hsp) family in patients with Helicobacter pylori infection. Clin Exp Immunol 1998;112:490-4.

26 Ward JM, Benveniste RE, Fox CH, et al. Autoimmunity in chronic active Helicobacter hepaticus of mice. Serum antibodies and expression of heat shock protein 70 in liver. Am f Pathol 1996;148:509-17. 